\title{
Craniofacial Dysmorphology and Hypodontia in 22q11.2 Deletion Syndrome
}

\author{
İdil Alatl Burt
}

\begin{abstract}
The purpose of this study was to determine the craniofacial morphology, as assessed on lateral cephalometric radiographs and to investigate the presence and/or the prevalence of hypodontia and distribution of hypodontia in the sample of patients with deletion 22q11 syndrome attending the Eastman Institute, in Stockholm, Sweden. This study indicates an increased cranial base angle $(\mathrm{Ba} /$ $\mathrm{SN}$ ) in patients with 22q11.2 deletion syndrome. A slight correlation was found between the increased cranial base and increased SN/ $\mathrm{NL}$ angle indicating a posterior rotation of the maxilla rather than the mandible. When each angle, apart from the cranial angle, was analyzed individually, they appeared to be relatively normal. The open bite features of these patients can be attributed to the hypotonic activity of the oromuscular forces rather than retrognathic features. There were no congenitally missing teeth in neither of the groups in this study.
\end{abstract}

Keywords: 22q11 deletion syndrome, CATCH 22, velocardiofacial syndrome, DiGeorge anomaly

\section{Introduction}

Chromosome rearrangements are notable embryonic death and birth defects. Chromosome 22q11.2 deletion syndrome (del 22q11 syndrome) is the most common microdeletion syndrome with an occurrence estimated at 1 in 4000 newborn infants $(1,2)$ and the annual incidence in south-west part of Sweden has been shown to be one in 7000 live births (3). This syndrome is characterized by significant phenotypic variability (4) which includes the majority of patients previously diagnosed with velo-cranio-facial syndrome (VCFS), DiGeorge syndrome (DGS) and conotruncal anomaly face syndrome (CFS). These three clinical entities are united by a common microdeletion (del22q11.2) in the proximal long arm

Department of Orthodontics, National Dental Health (FTV), Stockholm, Sweden

Corresponding Author:

İdil Alatlı Burt

National Dental Health (FTV) Department of Orthodontics

Lovisinsgatan 315173 Södertälje Stockholm, Sweden

Tel : : +46812315841

E-mail : Idil.burt@ftv.sll.se of chromosome 22 (5). Affected individuals carry the deletion on only one of the chromosomes 22 , so it is presumed to be a gene haploinsufficiency syndrome. In most cases, the deletion occur de novo, but in approximately $10 \%$ of cases it is inherited from a mildly affected parent thus behaving as an autosomal dominant trait (6-8).

The symptoms of del 22q11 syndrome are many and diverse. Each symptom might or might not be present in an affected individual and, if present, symptoms can occur with varying degrees of severity. So, distinct clinical features can show variable expressivity and incomplete penetrance. Nevertheless, there are some key clinical traits that can be classified according to whether they affect pharyngeal or neurobehavioural development. The "pharyngeal "phenotype encompasses the most characteristic features of del22q11 syndrome, namely congenital cardiovascular defects, craniofacial anomalies and aplasia or hypoplasia of the thymusgland and hypoparathyroidism/hypocalcemia. These features are thought to arise owing to the abnormal development of the pharyngeal apparatus during early fetal development (9). The "neurobehavioural" phenotype manifests in early childhood as learning difficulties, cognitive deficits and attention-deficit disorder. In adolescence and adulthood, some patients develop various psychiatric disorders, mainly schizophrenia. The basis of the neurobehavioural phenotype is unknown. All del22q11 syndrome patients manifest at least some components of the pharyngeal and neurobehavioral phenotypes with varying degrees of severity. In addition, some patients have various other symptoms, such as growth delay, minor skeletal and renal defects.

Several disturbances are related to the craniofacial region. These include auricular abnormalities, hypoplastic alae nasae leading to the appearance of a bulbous nasal tip, prominent nasal root (10), "hooded eyelids", maxillary hypoplasia, velopharyngeal incompetence, submucosal cleft palate, overt cleft palate, bifid uvula, cleft lip/cleft lip and palate, and retrognathia.

Furthermore, it seems that there is an association between genetic disorders and congenitally missing teeth. It is also known that hypocalcemia may result in a higher frequency of dental aberrations (11). It has been previously shown that there were changes in the enamel morphology such as hypomineralization, hypoplasia and extra incremental lines in the enamel within the patients with 22q11 deletion syndrome $(12,13)$. Numerous investigators have studied the association between hypodontia and significant alterations in 
Burt I.A.

craniofacial morphology in non-syndromic samples and craniofacial anomalies such as ectodermal dysplasia and Pierre Robin sequence $(14,15,16)$. Whether an association exists between the presence and/ or location of hypodontia and differential alterations in the regional craniofacial morphology in patients with del 11q11 syndrome is unknown.

Although the facial dysmorphology of patients with del 22q11 syndrome has been well described, the cephalometric characteristics of the syndrome and the dental parameters in the form of hypodontia have yet to be fully delineated. The first aim of the present study was to determine the craniofacial morphology, as assessed on lateral cephalometric radiographs and the second objective of this study was to investigate the presence and/or the prevalence of hypodontia and distribution of hypodontia (congenitally missing teeth) in the sample of patients with del 22q11 syndrome attending the Eastman Institute, in Stockholm, Sweden.

\section{Materials and Methods}

\section{Sample}

The sample consisted of 11 patients diagnosed with del 22q11 syndrome attending the Orthodontic Department of the Eastman Institute of Stockholm. These patients were chosen from a larger group of 76, using following criteria: del 22q11 syndrome confirmed by FISH analysis as part of a prospective, multidisciplinary study; no orthodontic treatment had been provided prior to the taking of high quality cephalometric radiographs and orthopantograms.

The sample comprised of 5 female and 6 male subjects aged between 7 years 5 months and 17 years 7 months of age at the initial observation. The mean age of the females and males was 14.13 years and respectively 13.61 years. Two subjects from male and six from female had submucosal cleft which were verified in the Eastman Institute, Craniofacial Department.

Healthy sex and age matched 43 subjects collected from the Eastman Institute, Department of Orthodontics data base were used as a control group. The age difference between the comparative pairs was less than 8 months.

8 of the subjects within the 22q11 deletion syndrome group had gone through velopharyngeal surgery and 4 of the subjects had had adenoidectomy prior to the cephalometric evaluations.

\section{Cephalometric and orthopantogramic analysis}

All radiographs were taken using the same cephalostat (Planmeca Proline EC Instruments Barracuda BCI-04040103 Detector MPD04040081; SEMKO nr 30082), with a magnification factor of 12 per cent. The radiographs were taken with the head in the natural head position according to the Frankfort horizontal, the teeth in the intercuspal position and the lips at rest. The radiographs were hand traced over a two week period by one examiner under the same controlled conditions. The cephalometric tracings were then digitized and measurements made using Dentofacial planner. The results were compared with age and sex matched Eastman norms and selected measurements from Steiner and Ricketts. The cephalometric values of the patients with 22q11 deletion syndrome were compared with the values of the control group.

Consequently taken orthopantograms were used to detect the missing teeth both in control group and patient group with $22 \mathrm{q} 11$ deletion syndrome.

The prevalence of congenitally missing teeth was calculated based on the chronological age of the patients, stage of calcification and follicle formation. Teeth were considered missing when there was no evidence in the records that they have been extracted and when the follicle formation or mineralization of tooth crown was not observed on the orthopantograms.

A retrospective investigation was conducted using health declaration from the patient journals to specify the mouth breathers and related snoring problem.

\section{Error study}

Eight weeks after the measurements were made, all radiographs were re- traced and re-digitized by the original examiner under the same. The combined errors in landmark location, tracing and measurement were estimated with $\mathrm{t}$-test for paired data. There were no statistically significant differences between the two sets of measurements.

The following anatomic points based on the classic definitions previously described in the literature were identified on each cephalogram $(17,18)$ (Figure 1).

Figure 1: The Landmark

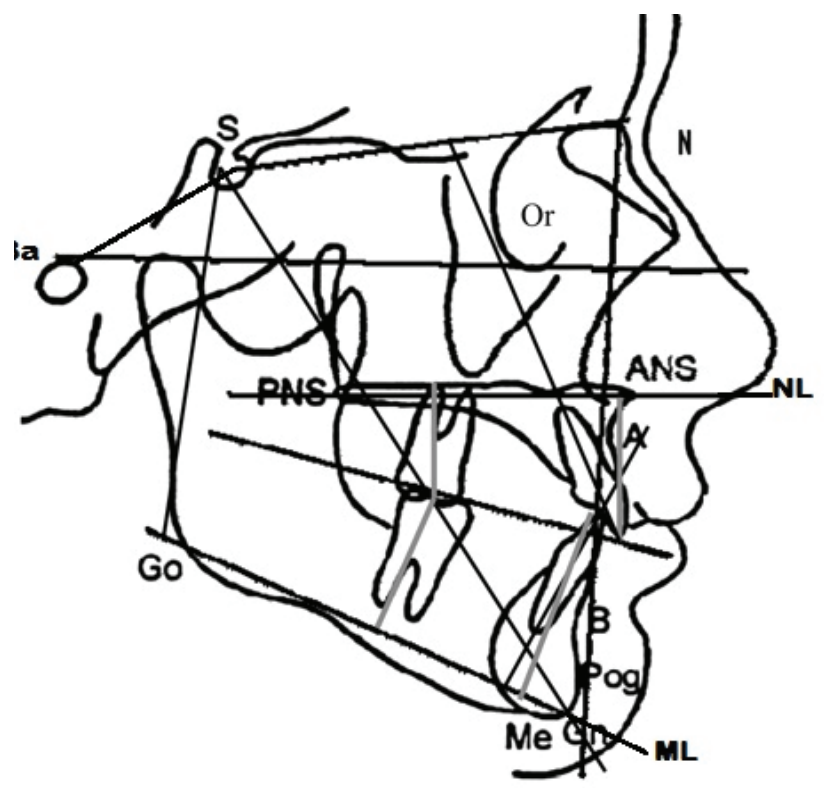

\section{Landmarks And Measurements}

\section{Cephalometric points}

1. $\mathbf{N}$ (nasion): The junction of the frontonasal suture at the most posterior point on the curve at the bridge of the nose.

2. S (sella turcica): The center of the pituitary fossa of the sphenoid bone. Determined by inspection.

3. ANS (anterior nasal spine): The tip of the median, sharp bony process of the maxilla at the lower margin of the anterior nasal opening. 
4. PNS (posterior nasal spine): The most posterior point at the sagittal plane on the bony hard plate.

5. A (subspinale or Down's A point): The most posterior point on the curve of the maxilla between the anterior nasal spine and the supradentale.

6. B (supramentale or Down's B point): The most posterior point to a line from the infradentale to Pogonion on the anterior surface of the symphyseal outline of the mandible.

7. Pog (Pogonion): The most anterior point on the profile outline of the mandibular symphysis. The point of contact with the line drawn from $\mathrm{N}$, tangent to the mandibular symphysis.

8. Gn (Gnathion): The most anterior - inferior point on the contour of the bony chin symhysis. Determined by bisecting the angle formed by the mandibular plane and a line through Pogonion and Nasion.

9. Me (Menton): The most inferior point on the symphyseal outline.

10. Go (Bony Gonion): The midpoint of the angle of the mandible. Found by bisecting the angle formed by the mandibular plane and a plane through Articulare, Posterior and along the portion of the mandibular ramus inferior to it.

11. Go (constructed Gonion, gonial intersection): The intersection of the tangents to the posterior and lower borders of the mandible.

12. Ar (Articulare): The point of intersection of the inferior cranial base surface and the averaged posterior surfaces of the mandibular condyles.

13. UIE (maxillary/Upper incisor incisal edge): The incisal tip of the maxillary central incisor.

14. UIA (maxillary/Upper incisor apex): The root tip of the most anterior maxillary central incisor. In cases where the root is not yet completed, the midpoint of the growing root tip is marked.

15. LIE (mandibular/Lower incisor incisal edge): The incisal tip of the most anterior mandibular central incisor.

16. LIA (mandibular incisor apex): The root tip of the most anterior mandibular central incisor. In cases where the root is not yet completed, the midpoint of the growing root tip is marked.

17. Pog (Soft tissue Pogonion): The most anterior point on the profile outline of the soft tissue mandibular symphysis.

\section{Cephalometric lines}

1. NL (palatal plane): A line formed by joining anterior nasal spine and posterior nasal spine.

2. ML (mandibular plane): A line formed by joining menton and bony gonion.

3. SN (Sella-nasion plane): A line formed by joining sella turkica and nasion.

4. S-lineThe line extending from the soft tissue contour of the chin to the middle of an $\mathrm{S}$ formed by the lower border of the nose.
5. The landmarks were used to construct various linear and angular cephalometric measurements and to evaluate the corresponding dental and skeletal relations (Figure 1).

\section{Angular measurements}

1. SNA Sagittal relation of the maxilla in relation to the anterior cranial base

2. SNB Sagittal relation of the mandible in relation to the anterior cranial base

3. ANB Sagittal relationship between the maxilla and the mandible

4. SN-NL Maxillary palatal plane inclination in relation to the anterior cranial base

5. NL-ML Palatal plane to the mandibular plane angle

6. SN-ML Mandibular plane inclination in relation to the anterior cranial base

7. Y axis (N-S-Gn) Position of the mandibular sympyhsis in the sagittal and vertical planes

8. Go (gonial angle) Angle formed between posterior and inferior border lines of the mandible.

9. 1-PP Inclination of maxillary incisor in relation to the palatal plane

10. 1-MP Inclination of mandibular incisor in relation to the mandibular plane Linear Soft Tissue Measurements

11. S-line Reference line between soft tissue pogonion and the midpoint on the inferior S-curvature of the nose (Steiner).

12. $\mathrm{U}$ - Lip Protrusion of the upper lip in relation to S-line

13. L - Lip Protrusion of the lower lip in relation to S-line

\section{Statistical Analysis}

Statistical analyses were performed by standard methods. Means and standard deviations for the cephalometric parameters were determined for each group. An analysis of variance test was performed to determine whether at least one of the groups was different from the other two. In this event, the Tukey-Kramer multiple comparison test was performed to determine significant differences among the three variables (age, sex and malocclusion). The Pearson correlation matrix was performed to establish whether there was any correlation between the measurements among the groups. The $t$ values corresponding to the different levels of significance were calculated according to the following formula:

$\frac{\left(\overline{X_{1}}-\overline{X_{2}}\right)}{\sqrt{\frac{S_{1}^{2}}{N_{1}}+\frac{S_{2}^{2}}{N_{2}}}}$

\section{Results}

The results are given in Tables I and II. Table III shows the statistical analysis of the data. The mean $\mathrm{Ba} / \mathrm{SN}$ value for the study population was $136,24 \pm 5,98$ compared to the control value of $\mathrm{Ba} / \mathrm{SN}$ which was $131,58 \pm 2,52$. The t-test was used to compare the mean $\mathrm{Ba} / \mathrm{SN}$, $\mathrm{SN} / \mathrm{ML}, \mathrm{SN} / \mathrm{NL}$ and NL/ML angles in the sample population to the 
Burt I.A.

control values. The control values were compared with the maximum normative values obtained by Riolo et al. (17). The computed t-value was 7, 91 for $\mathrm{Ba} / \mathrm{SN}$ values with 20 degrees of freedom and the obtained t-value corresponded to $\mathrm{p}<0.001$.

There were no significant differences between female and male subjects for any of the measured angles. The differences between the measured SN/ML, SN/NL and NL/ML angles of the patients with $22 \mathrm{q} 11$ deletion syndrome and controls were not statistically significant.

The regression of the cranial base angle on SN/NL angles in the patients with 22q11 deletion syndrome indicated a slight correlation between these two angles (Figure 2).

Table 1. Cephalometric analysis of patients with 22q11 deletion syndrome

\begin{tabular}{llllll}
\hline Sex & Age & Sa/SN & SN/ML & SN/NL & NL/ML \\
\hline F & $16 y 4 m$ & 137.7 & 33.2 & 10.9 & 22.3 \\
M & $11 y 8 m$ & 132.6 & 33.4 & 5.8 & 27.4 \\
F & $12 y 10 m$ & 145.4 & 42 & 7.5 & 34.6 \\
M & $17 y 7 m$ & 133.5 & 37.6 & 2 & 37.6 \\
M & $5 y 5 m$ & 141.3 & 42.6 & 12.8 & 29.8 \\
F & $7 y 3 m$ & 137.9 & 44.7 & 4 & 40.7 \\
M & $11 y 8 m$ & 133.4 & 35.2 & 6.9 & 28.3 \\
F & $7 y 7 m$ & 135.2 & 36.3 & 4.4 & 32 \\
M & $16 y 2 m$ & 143 & 36.6 & 12.1 & 24.5 \\
M & $11 y 9 m$ & 135.1 & 38.7 & 8.4 & 30.3 \\
F & $12 y 6 m$ & 123.5 & 40.5 & 3.7 & 36.9 \\
\hline Mean & 11.88 & 136.24 & 38.03 & 7.14 & 31.31 \\
SD & 4.3 & 5.9 & 3.81 & 3.61 & 5.71
\end{tabular}

Table 2. Cephalometric analysis of patients as controls without $22 \mathrm{q} 11$ deletion syndrome.

\begin{tabular}{ccccccc}
\hline Patient & Gender & $\begin{array}{c}\text { Age } \\
\text { (year) }\end{array}$ & Ba/SN & SN/ML & SN/NL & NL/ML \\
\hline 1 & F & 17 & 130.9 & 40 & 12.4 & 27.6 \\
2 & $\mathrm{~F}$ & 13 & 135.8 & 37.2 & 11.6 & 25.6 \\
3 & $\mathrm{M}$ & 16 & 136.5 & 31.2 & 9.2 & 22 \\
4 & $\mathrm{M}$ & 15 & 130.2 & 30.1 & 15.5 & 23.5 \\
5 & $\mathrm{M}$ & 11 & 132.4 & 32.2 & 13.9 & 20.9 \\
6 & $\mathrm{~F}$ & 12 & 128.8 & 29.6 & 9.2 & 23 \\
7 & $\mathrm{M}$ & 7 & 131.2 & 33.3 & 6.5 & 24.8 \\
8 & $\mathrm{~F}$ & 6 & 131.8 & 38.4 & 11.2 & 22.1 \\
9 & $\mathrm{M}$ & 16 & 130 & 39.1 & 13 & 23.9 \\
10 & $\mathrm{~F}$ & 13 & 131 & 31.3 & 6.9 & 25.2 \\
11 & $\mathrm{~F}$ & 7 & 128.8 & 25.9 & 6.8 & 20.7 \\
\hline & Mean & 11.44 & 131.58 & 33.48 & 10.56 & 23.57 \\
& $\mathrm{SD}$ & 4.56 & 2.40 & 4.55 & 3.06 & 2.12
\end{tabular}

Table 3. Comparison of cephalometric analysis of 22q11 deletion syndrome patients and controls.

\begin{tabular}{lccccc}
\hline & Age $($ year $)$ & $\mathrm{Ba} / \mathrm{SN}$ & $\mathrm{SN} / \mathrm{ML}$ & $\mathrm{SN} / \mathrm{NL}$ & $\mathrm{NL} / \mathrm{ML}$ \\
\hline & mean \pm & mean \pm & mean \pm & mean \pm & mean \pm \\
& $\mathrm{SD}$ & $\mathrm{SD}$ & $\mathrm{SD}$ & $\mathrm{SD}$ & $\mathrm{SD}$ \\
\hline Control & $11.8 \pm$ & $131.58 \pm$ & $33.48 \pm$ & $10.56 \pm$ & $23.57 \pm$ \\
$(\mathrm{n}=11)$ & 4.3 & 2.5 & 4.6 & 3.06 & 2.12 \\
C a t ch & $11.88 \pm$ & $136.24 . \pm$ & $38.25 \pm$ & $7.13 \pm$ & $31.3 \pm$ \\
$(\mathrm{n}=11)$ & 3.9 & 5.9 & 3.8 & 3.6 & 5.7 \\
& $\mathrm{NS}$ & $\mathrm{p}<0.001$ & $\mathrm{NS}$ & $\mathrm{NS}$ & $\mathrm{NS}$
\end{tabular}

Figure 2. The regression of the cranial base angle $(\mathrm{Ba} / \mathrm{SN})$ and $\mathrm{SN} / \mathrm{NL}$ in controls and in the patient group with $22 \mathrm{q} 11$ deletion syndrome.

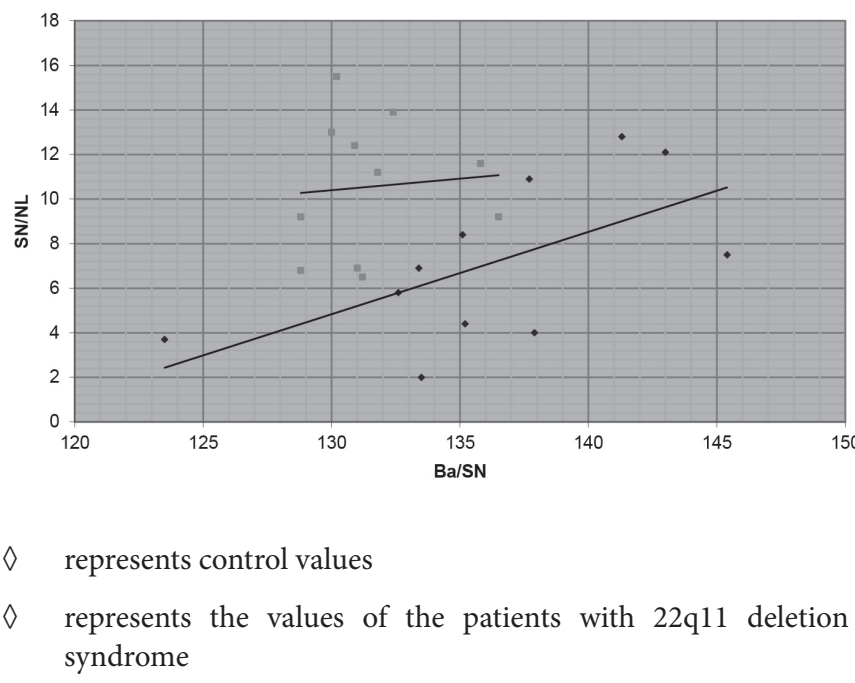

Health declaration from the patient journals to specify the mouth breathers and related snoring problem showed no significant changes between the two groups.

\section{Hypodontia results:}

The null hypothesis was that there is a higher prevalence of hypodontia in the del 22q11 syndrome comparing to the control group and the maxillary and mandibular hypodontia were associated with greater alteration of the regional craniofacial morphology within the syndrome. There were no congenitally missing teeth in neither of the groups in this study except two patients from del 22q11 syndrome group (17 years of age) was missing both maxillary laterals and from control group missing maxillary third molars.

\section{Discussion}

This is a study of small non-homogenous sample of patients with 22q11 deletion syndrome. There were few patients in each group. The location of the cephalometric landmarks used in this study has been shown to be acceptable (18). Using a computer to calculate the measurements reduced tracing errors due to measurement.

The finding of increased cranial base angle $(\mathrm{Ba} / \mathrm{SN})$ in patients with $22 \mathrm{q} 11$ deletion syndrome is in agreement with a previous study (19). This finding adds to the phenotypic features of these patients and 
this will be helpful in their differential diagnosis. When each angle apart from the cranial base angle, was analyzed individually, they appear to be relatively normal.

The spectrum of palatal anomalies like submucosal cleft of the palate associated with this syndrome may be expected to have significant craniofacial differences as a result of different surgical exposure as a neonate. However, the submucosal cleft in this study was not consistent except for two subjects from male and six from female.

It is well documented (9) that these patients with 22q11.2 deletion syndrome have retrognathia and this can be explained by a posterior positioning of the mandible. However, such a correlation was not found in this sample group. The findings of the present study concerning cranial base angle are in agreement with the previous studies $(20,21)$ ) who found that patients with $22 \mathrm{q} 11$ deletion syndrome have obtuse cranial base angles (paltybasia). In this study, there was slight correlation between the increased cranial base angle and increased SN/NL angle which indicates a posterior rotation of the maxilla rather than the mandible. This unexpected result found in this present study can well be due to different reference planes or different measure techniques used compared to the other studies. The small number of subjects available for this study may also account for this finding. It has also been found that the length of the maxilla in the 22q11 deletion syndrome group was longer than the control group which is in agreement with previous study (21). One explanation for the longer maxillary length within these patients would be that the larger anterior cranial base length affects the length of maxilla. There were neither significant differences in the length of the maxilla nor the mandible in this syndrome group. Furthermore, confirming the previous studies, long face with vertical excess in the anterior lower face height, vertical growth pattern, different angulations in the cranial base andinclination of the mandible and maxilla were found in this study.

The cranial base consists of the occipital, sphenoid and ethmoid bones. These structures together with the temporal bone compose the embryonic chondrocranium. The capsular matrix of the neural mass influences the cranial base configuration. The pharyngeal muscles and the functioning airspace influence the shape and the size of the surrounding bony structures. Keeping in mind, both neurogenic and mandibula-maxillary interaction as contributory factors, the weakness of the muscular forces surrounding the basicranium and the facial bony structures may explain the open bite features of these patients and the reason for their mouth breathing patterns. Patients with 22q11 deletion syndrome demonstrate a characteristic pattern of craniofacial dysmorphology and a relatively high incidence of craniofacial and oral anomalies underscoring the need for early identification and individualized treatment. Further studies with cephalometric tomographical volumetric analysis are needed to be able to gain more information about the facial, oropharyngeal and speech features of these patients.

Congenitally missing teeth is one of the most common dental developmental anomalies. Hypodontia is associated with a large number of various genetic diseases i.e. Down syndrome and ectodermal dysplasia as well as non-syndromic trait $(14,21,22)$. Etiology of hypodontia seems to be multifactoral and differences exist in terms of prevalence and distribution in various populations. It has been reported by Oberoi et. al. that congenitally missing teeth used as diagnostic aids in $22 \mathrm{q} 11$ deletion syndrome (23). It has been hypothesized that altered peripheral nerves system growth and abnormal development of localized chondral elements may contribute as potential mechanisms responsible for the greater occurrence of hypodontia (24).A more recent report described that trigeminal nerve fiber growth and patterning are integrated with tooth morphogenesis and it is suggested that mesenchymal dental follicles fail to form as a result of inadequate local epithelialmesenchymal interaction due to thyroid deficiency, causing delayed proliferation of nerve cells and decreased rate of neuron production (22). In two different studies a prevalence of congenitally missing teeth (15\%) in patients with 22q11.2 deletion syndrome in Norway (26) and a prevalence of hypodontia of $9 \%$ in Brazil were reported (27). However, in the previous study no congenitally missing teeth were found in neither of the groups except one patient within the $22 \mathrm{q} 11$ deletion syndrome group was congenitally missing both maxillary laterals and one from the control group missing maxillary third molars. Bredy et al. (25) indicated a frequency of $81.5 \%$ for third molar agenesis found in all agenesis non-syndromic patients. The number of patients in this study was not sufficient to conclude that there is an increased amount of hypodontia in the 22 q11 deletion syndrome group. Future studies should further investigate the aspect of congenitally missing teeth within the 22q11 deletion syndrome in larger samples compared to control groups as well as employing molecular genetic techniques.

\section{Conclusion}

There was an increased cranial base angle $(\mathrm{Ba} / \mathrm{SN})$ in patients with 22q11.2 deletion syndrome. A slight correlation was found between the increased cranial base and increased SN/NL angle indicating a posterior rotation of the maxilla rather than the mandible. When each angle, apart from the cranial angle, was analyzed individually, they appeared to be relatively normal. The open bite features of these patients can be attributed to the hypotonic activity of the oromuscular forces rather than retrognathic features. There were no significant hypodontia in neither of the groups in this study.

\section{References}

1. Defriend K, Fry's JP, Mortier G, van Thienen MN, Keymolen K. The annual incidence of DIGeorge/velocardiofacial syndrome. JMed Genet 1998 Sep;35(9):789-790

2. Scambler PJ. The 22q11 deletion syndromes. Hum Mol Genet 2000 Oct, 9 (16):2421-2426

3. Oskardottir S, Vujic M, Fasth A. Incidence and prevalence of the 22q11 deletion syndrome; a population based study in Western Sweden. Arch Dis Child 2004; 89:148-51

4. Shprintzen RJ. Velo-cardio-facial syndrome: a distinctive behavioral phenotype. Mental retardation and dev. Dis Res. Reviews 2000 (6): 142 147

5. De la Chapelle A, Herva R, Koivisto M, Aula P. A deletion in chromosome 22 can cause DGS. Hum Gen 1981, 57:253-6.

6. Driscoll DA, Budarf ML, Emanuel BS A genetic etiology for DiGeorge syndrome: consistent deletions and microdeletions of 22q11. Am J Hum Genet 1992, 50: 924-33

7. Kelley RI,Zackai EH, Emanuel BS, Kistenmacher M, Greenberg F, Punnett $\mathrm{HH}$ The association of the DiGeorge anomalad with partial 
Burt I.A.

monosomy of chromosome 22. J Pediatr 1982, 101: 197-200.

8. Yamagishi H, Srivastava d. Unraveling the genetic and developmental mysteries of 22q11 deletion syndrome. Trends Mol Med 2003; 9: 383389

9. Conley ME,Beckwith JB, Mancer JF,Tenckhoff L. The spectrum of DiGeorge syndrome. J of Pediatr 1979; 94:883-890.

10. Gripp KW, McDonald-McGinn DM, Driscoll DA,Reed LA, Emanuel BS, Zackai EH, Nasal dimple as part of the 22q11 deletion syndrome. Am J Med Genet 1997; 69:290-2.

11. Suckling GW. Developmental defects of enamel-historical and presentday perspectives of their pathogenesis. Adv Dent Res 1989; 3:87-94.

12. Klingberg G, Oskardottir S,Johannesson EL, Noren JG. Oral manifestations in 22q11 deletion syndrome. Int J Paediatr Dent 2002; $12: 14-23$

13. Klingberg G, Dietz W, Oskarsdottir S, Odelius H, Gelander L, Noren JG. Morphological appearance and chemical composition of enamel in primary teeth from patients with 22q11 deletion syndrome. Eur J Oral Sci 2005; 113:303-1.

14. Lucas J. The syndromic tooth-the aetiology, prevalence,presentation and evaluationof hypodontia with children with syndromes. Ann R Australas Coll Dent Surg 2000; 15:211-217.

15. Suri S, Tompson BD,Atenafu E. Prevalence and patterns of permanent tooth agenesis in Down syndrome and their association with craniofacial morphology. Angle Ortod. 2011 Mar; 81 (2):260-269.

16. Johnson EL,Roberts MW,Guckes AD,Bailey LJ,Philips CL, Wright JT. Analysis of craniofacial development in children with hypohidrotic ectodermal dysplasia. Am J Med Genet 2002;112:327-334.

17. Riolo ML,Moyers RE, McNamara JA Jr, Hunter WS: "Atlas of Craniofacial Growth”. Ann Arbor: Univ. Of Michigan Center for Human Growth and Development, 1979.

18. Vincent A.M., West V.C. Cephalometric landmark identification error. Aust Orthod J 1987; 10:98-104.

19. Shprintzen RJ, Velo-cardio faceial syndrome: 30 years of study. Dev Disabil Res Rev 2008;14:3-10.

20. Arvystas M, Shprintzen RJ. Craniofacial morphology in the velocardio-facial syndrome. J Craniofac Genet Dev Biol 1984;4: 39-45.

21. Heliövaara A,Hurmerinta K. Craniofacial cephalometric morphology in children with CATCH 22 syndrome. Orthod Craniofacial Res 9; 2006: 186-192.

22. Reuland-Bosma, W, Reuland MC, Bronkhorst E, Phoa KH . Patterns of tooth agenesis in patients with Down syndrome in relation to hypothyroidism and congenital heart disease: an aid for treatment planning. Am J Orthod Dentofacial Orthop 2010; 137:584.e1-584.e9.

23. Oberoi S, Huynh L, Vargervik K. Velopharyngeal, speech and dental characteristics as diagnostic aids in 22q11.2 deletion syndrome. J Calif Dent Assoc. 2011 May; 39(5):327-32.

24. Russel BG, Kjaer I. Tooth agenesis in Down syndrome. Am J Med Genet $1995 ; 55: 466-471$.

25. Bredy E, Erbring C,Hubenthal B. The incidence of hypodontia with the presence and absence of wisdom teeth. Dtsch Zahn Mund Kieferheillkd Zentralbl. 1991; 79:357-363.
26. Nordgarden H, Lima K, Skogedal N, Folling I, Storhaug K, Abrahansen TG. Dental developmental disturbances in 50 individuals with the 22q11.2 deletion syndrome; relation to medical conditions? Acta Odont Scan 2012; early online, 1-8.

27. da Silva Dalben G, Richieri_Costa A, de Assisa Taveira LA. Tooth abnormalities and soft tissue changes in patients with velocardiofacial syndrome. Oral Surg Oral Med Oral Pathol Oral radiol Endod 2008; 19:258-261. 